\title{
Network Information Security Research based on the Grey Matter Element Analysis Method
}

\author{
Qingji Tian \\ Weifang University of Science and Technology, Weifang, Shandong \\ 20236549@qq.com
}

\begin{abstract}
With the progress of science and technology and the development of society, computer network information security becomes a social problem. In this paper, according to the characteristics of computer network information, the influencing system of computer network information security is constructed. Using matter element analysis method and grey theory to establish the grey matter-element model of the computer network information security, computer network information security can be divided into four grey clustering levels, according to the results of the expert scoring to determine the grey clustering level of computer network information security, which provides a professional, scientific and reasonable method for studying computer network information security.
\end{abstract}

Keywords: network information; grey element; whitening value; security; weight

\section{Introduction}

In recent years, the rapid development of computer technology and computer network provides convenience for people, which plays a huge role in promoting the development of the whole society. Computer network is widely applied in every aspect of human social life. It has become an important part in people's lives. The spread of network information affects the whole society. But at the same time, it brings many challenges as well. With the growth of people's demand for network information resources, the information security issues become more and more prominent, and viruses, hacker, network crimes bring a great challenge to network information security. Therefore, computer network security is a very important and urgent task.

\section{The Influencing System of Computer Network Information Security}

\subsection{The Selecting Principles of Main Influencing Factors of Computer Network Information Security}

Computer network information is enormous. There are many factors affecting information security. In the selecting process of influencing factors, certain principles should be followed, not only ensuring to contain all aspects and levels, but also being simple and easy to calculate and satisfy.

(1) The combination of comprehensiveness, systematisms and emphasis factors

In the selecting process of main influencing factors of computer network information security, we should not only comprehensively consider the various influence of computer network information security, but also form a system. At the same time, according to the different emphasis, the local emphasis factors should be considered, achieving the combination of comprehensiveness, systematisms and emphasis factors.

(2) The combination of accuracy and fuzziness

The research of computer network information security should be based on a large amount of data as support. Therefore, the selected influencing factors should collect 
accurate data. At the same time, some factors just need to evaluate the general direction, which means, achieving the combination of accuracy and fuzziness.

(3) The combination of diversity and changeability

With the development of science and technology, the update of computer network is very quick. At the same time, different network information is different. Therefore, the diversity and changeability should be combined.

(4) The combination of feasibility and stability

The influencing system of computer network information security must have the feasibility. Through this system, the feasibility study could be carried on. At the same time, the stability should be maintained. The influence factors cannot be changed at any time.

\subsection{The System and its Influence of Computer Network Information Security}

According to the selecting principles of main factors that influence the computer network information security, combined with the actual situation of the current computer network information security, the influencing system is built up in Table 1.

Table 1. The Influencing Factors of Computer Network Information and its Influence on the Second-level Factors

\begin{tabular}{|c|c|c|c|}
\hline target & $\begin{array}{r}\text { main } \\
\text { factors }\end{array}$ & $\begin{array}{c}\text { second- } \\
\text { level factors }\end{array}$ & $\begin{array}{l}\text { the influence the second-level factors } \\
\text { to computer network information }\end{array}$ \\
\hline \multirow{6}{*}{$\begin{array}{r}\text { Comput } \\
\text { er network } \\
\text { information } \\
\text { security P }\end{array}$} & \multirow{6}{*}{$\begin{array}{l}\text { Network } \\
\text { security } \\
\text { protection } \\
\text { A }\end{array}$} & Firewall & $\begin{array}{l}\text { Firewall has very good protection. } \\
\text { Configure firewall into different } \\
\text { protection levels, computer network } \\
\text { security is also different. }\end{array}$ \\
\hline & & $\begin{array}{l}\text { proxy } \\
\text { server }\end{array}$ & $\begin{array}{l}\text { The proxy server is a service security } \\
\text { function, mainly from the conversation } \\
\text { layer of the open system interconnection } \\
\text { (OSI) model to the firewall. }\end{array}$ \\
\hline & & $\begin{array}{l}\text { Anti-virus } \\
\text { system }\end{array}$ & $\begin{array}{l}\text { Can prevent most viruses that attack } \\
\text { buffer overflow vulnerability. }\end{array}$ \\
\hline & & $\begin{array}{l}\text { Password } \\
\text { system }\end{array}$ & $\begin{array}{l}\text { The password system could realize the } \\
\text { encryption protection of computer } \\
\text { network information, and prevent } \\
\text { information leakage. }\end{array}$ \\
\hline & & $\begin{array}{l}\text { Security } \\
\text { database }\end{array}$ & $\begin{array}{l}\text { Security database is a database } \\
\text { management system that on the basis of } \\
\text { general function of relational database, } \\
\text { improves the security of database, } \\
\text { achieving the standards of TCSEC and } \\
\text { the B1 level of TDI (security label } \\
\text { protection) or the third level (security } \\
\text { label protection level) of Chinese } \\
\text { national standard < The security } \\
\text { protection classification standards of } \\
\text { computer information system > or above } \\
\text { it. }\end{array}$ \\
\hline & & $\begin{array}{l}\text { Authenticat } \\
\text { ion system }\end{array}$ & $\begin{array}{l}\text { The system could realize the safety } \\
\text { identification of computer network } \\
\text { information, prevent the dangerous } \\
\text { information like viruses, Trojans into the }\end{array}$ \\
\hline
\end{tabular}




\begin{tabular}{|c|c|c|}
\hline & & computer. \\
\hline & $\begin{array}{l}\text { safe } \\
\text { operation } \\
\text { system }\end{array}$ & $\begin{array}{l}\text { Safe operation system meets the safety } \\
\text { technical requirements of computer } \\
\text { information system such as discretionary } \\
\text { access control, mandatory access control, } \\
\text { marking, identification, object reuse, } \\
\text { auditing, data integrity, covert channel } \\
\text { analysis, trusted path, trusted recovery. }\end{array}$ \\
\hline & $\begin{array}{l}\text { Personnel } \\
\text { security } \\
\text { protection }\end{array}$ & $\begin{array}{l}\text { Personnel security protection is the } \\
\text { protection for exposure workers of } \\
\text { computer network information, which } \\
\text { could prevent unnecessary people contact } \\
\text { with the security information. }\end{array}$ \\
\hline \multirow{4}{*}{$\begin{array}{l}\text { Network } \\
\text { security } \\
\text { detection B }\end{array}$} & $\begin{array}{l}\text { Intrusion } \\
\text { detection }\end{array}$ & $\begin{array}{l}\text { Through collecting information and } \\
\text { carries on the analysis to the key points } \\
\text { in computer network or computer system } \\
\text { to find whether there is violation of } \\
\text { security policy or signs of being attacked } \\
\text { in the network or system. }\end{array}$ \\
\hline & $\begin{array}{l}\text { System } \\
\text { vulnerability } \\
\text { scanning }\end{array}$ & $\begin{array}{l}\text { System vulnerability scanning } \\
\text { is security detection behavior based on } \\
\text { the vulnerability database to find the } \\
\text { available vulnerability. }\end{array}$ \\
\hline & $\begin{array}{l}\text { frangibility } \\
\text { scanning }\end{array}$ & $\begin{array}{l}\text { By means of scanning, check the } \\
\text { security frangibility of the designated } \\
\text { remote or local computer system. }\end{array}$ \\
\hline & $\begin{array}{c}\text { Trojan } \\
\text { virus detection }\end{array}$ & $\begin{array}{l}\text { Can timely detect the Trojan virus, } \\
\text { and carries on the isolation and cleared. }\end{array}$ \\
\hline \multirow{3}{*}{$\begin{array}{l}\text { Network } \\
\text { emergency } \\
\text { response C }\end{array}$} & $\begin{array}{l}\text { Passive } \\
\text { emergency } \\
\text { response }\end{array}$ & $\begin{array}{l}\text { After the information security threat, a } \\
\text { series of operations such as system } \\
\text { backup, virus detection, back door } \\
\text { detection, removing the virus or the back } \\
\text { door, isolation, system recovery, } \\
\text { investigation and tracking, invaders } \\
\text { forensics and etc.. should be taken. }\end{array}$ \\
\hline & $\begin{array}{l}\text { active } \\
\text { emergency } \\
\text { response }\end{array}$ & $\begin{array}{l}\text { Before the information security threat, } \\
\text { some preparation should be made in } \\
\text { advance, such as carrying on the risk } \\
\text { evaluation, developing security plans, } \\
\text { training security consciousness, making } \\
\text { the security announcement or other } \\
\text { protection measures. }\end{array}$ \\
\hline & $\begin{array}{l}\text { Emergency } \\
\text { response } \\
\text { speed }\end{array}$ & $\begin{array}{l}\text { Emergency response speed decides the } \\
\text { harm size and the level of information } \\
\text { security. }\end{array}$ \\
\hline \multirow[t]{2}{*}{$\begin{array}{l}\text { Informat } \\
\text { ion disaster } \\
\text { recovery D }\end{array}$} & $\begin{array}{l}\text { system } \\
\text { repair }\end{array}$ & $\begin{array}{l}\text { System repair is the repair after } \\
\text { information security being attacked. The } \\
\text { speed and degree of its repair decide the } \\
\text { efficiency of computer information } \\
\text { security prevention. }\end{array}$ \\
\hline & data backup & Data backup is the basis of disaster \\
\hline
\end{tabular}




\begin{tabular}{|c|c|c|}
\hline repair & $\begin{array}{c}\text { recovery. In order to prevent the system } \\
\text { misoperation or data loss because of } \\
\text { system fault, gather all or part of data and } \\
\text { copy it from the host hard disk or array to } \\
\text { the other storage medium. }\end{array}$ \\
\cline { 2 - 3 } & $\begin{array}{c}\text { Security policy is a set of rules used in } \\
\text { all activities related to security in a } \\
\text { security } \\
\text { celicy } \\
\text { upgrade }\end{array}$ & $\begin{array}{c}\text { directly decides the degree of network } \\
\text { information security. }\end{array}$ \\
\hline
\end{tabular}

\section{Grey Matter Element Model of Computer Network Information Security}

Grey matter element model is the model of studying object influential effect combined with the grey theory and the matter-element analysis method. It is suitable for solving the fuzzy problems, transferring the ambiguous problems into the compatible and quantized problems.

\subsection{Determine the Grey Number Whitening Value of Computer Network Information Security}

Here we adopt grey element expression, that is, use the ordered triple of computer network information security, the characteristics of computer network security, and the grey number whitening value to describe computer network information security, and $\tilde{\otimes} R$ is used to express.

$$
\tilde{\otimes} R=\left[\begin{array}{ll} 
& N \\
c & \tilde{\otimes}
\end{array}\right],
$$

$N$ indicates computer network information security, $c$ indicates the characteristics of computer network security(the second-level influencing factors of computer network information security), $\tilde{\otimes}$ indicates the grey number whitening value corresponding to the second-level influencing factors of computer network information security.

3.1.1. Determine the grey clustering levels of computer network information security: According to the analysis of the influencing factors of computer network information security, referring to a large number of literature and material, combined with the computer network experts' opinion, the grey clustering levels of computer network information security could be divided into four levels, that is, very safe, safe, general, unsafe. The specific details are shown in Table 2.

\section{Table 2. The Level Classification Table of Computer Network Information Security (10 Points System is used)}

\begin{tabular}{|c|c|}
\hline Computer network information security level & Scale (no unit) \\
\hline Very safe & $\geqq 8$ \\
\hline safe & $6 \sim 8$ \\
\hline general & $4 \sim 6$ \\
\hline unsafe & $\leqq 4$ \\
\hline
\end{tabular}

3.1.2. Determine the whitenization weight function of computer network information security: There are three kinds of expressions of the whitenization weight function, that is: 
1. The upper type, the grey number is $\otimes \in\left[0, d_{1},+\infty\right)$, its whitenization weight function is:

$$
f_{1}\left(d_{j i}\right)=\left\{\begin{array}{cc}
\frac{d_{j i}}{d_{1}}, & d_{j i} \in\left[0, d_{1}\right] \\
1, & d_{j i} \in\left[d_{1},+\infty\right) \\
0, & d_{j i} \notin[0,+\infty)
\end{array}\right.
$$

2. The middle type, the grey number is $\otimes \in\left[0, d_{1}, 2 d_{1}\right]$, its whitenization weight function is:

$$
f_{2}\left(d_{j i}\right)=\left\{\begin{array}{cc}
\frac{d_{j i}}{d_{1}}, & d_{j i} \in\left[0, d_{1}\right] \\
2-\frac{d_{j i}}{d_{1}}, & d_{j i} \in\left[d_{1}, 2 d_{1}\right] \\
0, & d_{j i} \notin\left[0,2 d_{1}\right]
\end{array}\right.
$$

3. The lower type, the grey number is $\otimes \in\left[0, d_{1}, d_{2}\right]$, its whitenization weight function is:

$$
f_{3}\left(d_{j i}\right)=\left\{\begin{array}{cc}
1, & d_{j i} \in\left[0, d_{1}\right] \\
\frac{d_{2}-d_{j i}}{d_{2}-d_{1}}, & d_{j i} \in\left[d_{1}, d_{2}\right] \\
0, & d_{j i} \notin\left[0, d_{2}\right]
\end{array}\right.
$$

The selection of $d_{1}, d_{2}$ in formula (1) (2) (3) is usually carried on according to the related standards or the previous experience, or could be valued according to the minimum, average, maximum of the sample matrix to determine the threshold value of lower limit, middle and upper limit.

Referring to Table 2 and the actual situation of computer network information security, the 4 grey clustering function expressions of computer network information security could be determined as follows:

$$
\begin{gathered}
f_{1}(d)=\left\{\begin{array}{ll}
\frac{d}{8}, & 0 \leq d \leq 8 \\
1, & d>8 \\
0, & d<0
\end{array}, \quad f_{2}(d)=\left\{\begin{array}{cc}
\frac{d}{8}, & 0 \leq d \leq 8 \\
2-\frac{d}{8}, & 8<d \leq 16, \\
0, & d>16, d<0
\end{array}\right.\right. \\
f_{3}(d)=\left\{\begin{array}{cc}
\frac{d}{6}, & 0 \leq d \leq 6 \\
2-\frac{d}{6}, & 6<d \leq 12 \\
0, & d>12, d<0
\end{array}, \quad f_{4}(d)=\left\{\begin{array}{cc}
1, & 0 \leq d \leq 4 \\
2-\frac{d}{4}, & 4<d \leq 8 . \\
0, & d>8, d<0
\end{array}\right.\right.
\end{gathered}
$$




\subsubsection{Determine the Grey Coefficients of Computer Network Information Security:}

Using the expert evaluation method to score computer network information security, we could get $D_{j i}, D_{i i}^{(A)}$ indicates the scoring matrix the expert $i$ give to the $j$ th secondlevel factors of the main factor $A$.

Integrated matrix $D_{j i}^{(A)}$ and the whitenization weight function $f_{k}\left(d_{j i}\right)$, we could get the grey evaluation coefficient $j$ th second-level factor of the main factor $A$ to the main factor $A$ which belong to $k$ th grey clustering as follows:

$$
\tilde{\Theta}_{j i}^{(A)}=\sum_{i=1}^{n} f_{k}\left(d_{j i}\right)
$$

\subsection{The Grey Matter Elements of Each Main Factor of Computer Network Information Security}

$\tilde{\otimes}_{j i}(j=1,2, \cdots, m ; i=1,2, \cdots, n)$ is the corresponding grey number whitening value of $n$ main factors of computer network information security under $j$ th grey clustering level, therefore we could get $n$-dimension grey element of $j$ th grey clustering level.

$$
\tilde{\otimes} R_{j n}=\left[\begin{array}{cc} 
& M_{j} \\
c_{1} & \tilde{\otimes}_{j 1} \\
c_{2} & \tilde{\otimes}_{j 2} \\
\vdots & \vdots \\
c_{n} & \tilde{\otimes}_{j n}
\end{array}\right],
$$

$M_{j}$ indicates the $j$ th grey clustering level, $c_{j}$ indicates the $i$ th main factor of $j$ th grey clustering level, $\tilde{\otimes}_{j i}(j=1,2, \cdots, m ; i=1,2, \cdots, n)$ indicates the corresponding grey number whitening value.

Gather the $n$-dimension grey element of $m$ grey clustering levels, write $n$ dimension composite grey element of $m$ grey clustering levels, use $\tilde{\otimes} R_{m n}$ to express, namely:

$$
\tilde{\otimes} R_{m n}=\left[\begin{array}{ccccc} 
& M_{1} & M_{2} & \cdots & M_{m} \\
c_{1} & \tilde{\Theta}_{11} & \tilde{\Theta}_{21} & \cdots & \tilde{\otimes}_{m 1} \\
c_{2} & \tilde{\otimes}_{12} & \tilde{\Theta}_{22} & \cdots & \tilde{\otimes}_{m 2} \\
\vdots & \vdots & \vdots & & \vdots \\
c_{n} & \tilde{\otimes}_{1 n} & \tilde{\Theta}_{2 n} & \cdots & \tilde{\otimes}_{m n}
\end{array}\right] .
$$

\section{3. $n$-Dimension Grey Element of the Ideal Risk Set of Computer Network Information Security}

Find out the optimal value from $m$ grey clustering levels, make up an ideal risk set so as to construct the $n$-dimension grey element of the ideal risk set. 


$$
\tilde{\otimes} R_{0}=\left[\begin{array}{cc} 
& M_{0} \\
c_{1} & \tilde{\otimes}_{01} \\
c_{2} & \tilde{\otimes}_{02} \\
\vdots & \vdots \\
c_{n} & \tilde{\otimes}_{0 n}
\end{array}\right] .
$$

Normally, the optimal value is determined according to the minimum value, the medium value and the maximum value of grey number whitening value of each main factor, namely, there are 3 types:

(1)The smaller the optimal type: : $\tilde{\otimes} R_{0 i}=\tilde{\otimes} R_{1 i} \wedge \tilde{\otimes} R_{2 i} \wedge \cdots \wedge \tilde{\otimes} R_{m i}$;

(2)The moderate type: $\tilde{\otimes} R_{0 i}=u_{j i}$;

(3)The bigger the optimal type: $\tilde{\otimes} R_{0 i}=\tilde{\otimes} R_{1 i} \vee \tilde{\otimes} R_{2 i} \vee \cdots \vee \tilde{\otimes} R_{m i}$,

And $i=1,2, \cdots, n, \wedge$ is min- operation, $\vee$ is max-operation.

\subsection{The Correlation Analysis of Computer Network Information Security}

\subsubsection{Expert Scoring Data Processing}

Use the interval data processing to carry on the dimensionless processing to the original data. There are three kinds of concrete forms, that is:

(1)The smaller the optimal type: $\tilde{\otimes}_{j i}^{\prime}=\frac{\max \tilde{\otimes}_{j i}-\tilde{\otimes}_{j i}}{\max \tilde{\otimes}_{j i}-\min \tilde{\otimes}_{j i}}$;

(2)The moderate type: $\tilde{\otimes}_{j i}^{\prime}=\frac{\min \left(\tilde{\Theta}_{j i}-u_{j i}\right)}{\max \left(\tilde{\otimes}_{j i}-u_{j i}\right)}$;

(3)The bigger the optimal type: $\tilde{\otimes}_{j i}^{\prime}=\frac{\tilde{\otimes}_{j i}-\min \tilde{\otimes}_{j i}}{\max \tilde{\otimes}_{j i}-\min \tilde{\otimes}_{j i}}$,

And $j=1,2, \cdots, m, i=1,2, \cdots, n$.

\subsubsection{The Correlation Analysis of Computer Network Information Security}

Calculate the $n$-dimension correlation coefficient composite grey element of $m$ grey clustering levels as follows:

$$
\tilde{\otimes} R_{\xi}=\left[\begin{array}{ccccc} 
& M_{1} & M_{2} & \cdots & M_{m} \\
c_{1} & \tilde{\otimes} \xi_{11} & \tilde{\otimes} \xi_{21} & \cdots & \tilde{\otimes} \xi_{m 1} \\
c_{2} & \tilde{\otimes} \xi_{12} & \tilde{\otimes} \xi_{22} & \cdots & \tilde{\otimes} \xi_{m 2} \\
\vdots & \vdots & \vdots & & \vdots \\
c_{n} & \tilde{\otimes} \xi_{1 n} & \tilde{\otimes} \xi_{2 n} & \cdots & \tilde{\otimes} \xi_{m n}
\end{array}\right],
$$

$\tilde{\otimes} \xi_{j i}$ indicates the correlation coefficient whitening value of $i$ th main factor under the $j$ th grey clustering level after the standardization transformation, $j=1,2, \cdots, m$, $i=1,2, \cdots, n$ the elements in the matrix are as follows:

$\tilde{\otimes} \xi_{j i}=\frac{\Delta \min +\rho \Delta \max }{\Delta_{j i}+\rho \Delta \max }$ 
$\Delta_{j i}=\left|\tilde{\otimes}_{0 i}^{\prime}-\tilde{\otimes}_{j i}^{\prime}\right| \quad, \quad \Delta \max$ indicates the maximum value of absolute error $\Delta_{j i}, \Delta$ min indicates the minimum value of absolute error $\Delta_{j i}, \rho$ indicates the resolution coefficient, normally, $\Delta \min =0, \rho=0.5$.

\subsubsection{Calculate the Correlation of Computer Network Information Security.}

Using the fuzzy hierarchy method to calculate each factor weight of computer network information security $\omega_{k}, \omega_{k n}, \omega_{k}$ indicates the weights of the main factors, $\omega_{k n}$ indicates the second-level factor weight under $k$ th main factor. Each factor weight of computer network information security is shown in Table 3.

Table 3. Each Factor Weight of Computer Network Information Security

\begin{tabular}{|c|c|c|c|}
\hline main factors & Weight & Second-level factors & weight \\
\hline \multirow{8}{*}{ Network security protection A } & \multirow{8}{*}{0.3847} & Firewall & 0.1996 \\
\hline & & proxy server & 0.1123 \\
\hline & & Anti-virus system & 0.0956 \\
\hline & & Password system & 0.1178 \\
\hline & & Security database & 0.0862 \\
\hline & & Authentication system & 0.1530 \\
\hline & & safe operation system & 0.1103 \\
\hline & & Personnel security protection & 0.1252 \\
\hline \multirow{4}{*}{ Network security detection B } & \multirow{4}{*}{0.1485} & Intrusion detection & 0.3803 \\
\hline & & System vulnerability scanning & 0.2536 \\
\hline & & frangibility scanning & 0.2305 \\
\hline & & Trojan virus detection & 0.1356 \\
\hline \multirow{3}{*}{ Network emergency response $\mathrm{C}$} & \multirow{3}{*}{0.2761} & Passive emergency response & 0.2667 \\
\hline & & active emergency response & 0.3333 \\
\hline & & Emergency response speed & 0.4000 \\
\hline \multirow{3}{*}{ Information disaster recovery $\mathrm{D}$} & \multirow{3}{*}{0.1907} & system repair & 0.1400 \\
\hline & & data backup repair & 0.6200 \\
\hline & & security policy upgrade & 0.2400 \\
\hline
\end{tabular}

From Table 3 we could get:

$$
\begin{gathered}
\omega=(0.3847,0.1485,0.2761,0.1907), \\
\omega_{A}=(0.1996,0.1123,0.0956,0.1178,0.0862,0.1530,0.1103,0.1252), \\
\omega_{B}=(0.3803,0.2536,0.2305,0.1356), \omega_{C}=(0.2667,0.3333,0.4000), \\
\omega_{D}=(0.1400,0.6200,0.2400) .
\end{gathered}
$$

Carry on the weighted calculation to each factor of computer network information security, and we could get the overall grey correlation degree the major factors of computer network information security to level $k$ of grey clustering.

$\tilde{\otimes} A_{k}=\omega_{k} \cdot \tilde{\otimes} R_{\xi}$

According to the maximum membership degree principle, the grey clustering level of computer network information security could be determined. 


\section{The Simulation Calculation of Computer Network Information Security of Weifang University of Science and Technology}

Five computer network experts are hired to score the computer network information security of Weifang University of Science and Technology. The results are shown in Table 4.

Table 4. The Scores the Experts Give to the Computer Network Information Security of Weifang University of Science and Technology

\begin{tabular}{|c|c|c|c|c|c|}
\hline Second-level factors & Expert 1 & Expert 2 & Expert 3 & Expert 4 & Expert 5 \\
\hline Firewall & 4.3 & 5.8 & 5.5 & 6.8 & 7.8 \\
\hline proxy server & 8.2 & 7.8 & 8.3 & 7.5 & 8.5 \\
\hline Anti-virus system & 8.1 & 8.5 & 8.8 & 7.6 & 8.6 \\
\hline Password system & 3.5 & 5.2 & 4.3 & 3.0 & 6.0 \\
\hline Security database & 4.2 & 3.8 & 3.6 & 4.5 & 6.5 \\
\hline Authentication system & 3.8 & 4.3 & 4.8 & 3.2 & 5.2 \\
\hline safe operation system & 4.5 & 5.6 & 4.8 & 6.0 & 8.1 \\
\hline Personnel security protection & 4.0 & 3.2 & 4.1 & 3.9 & 5.9 \\
\hline Intrusion detection & 5.1 & 6.2 & 6.8 & 4.2 & 6.2 \\
\hline System vulnerability scanning & 6.2 & 5.4 & 4.2 & 4.8 & 6.8 \\
\hline frangibility scanning & 4.3 & 4.8 & 3.8 & 4.2 & 6.2 \\
\hline Trojan virus detection & 5.2 & 5.5 & 4.8 & 3.8 & 5.8 \\
\hline Passive emergency response & 6.6 & 5.6 & 5.2 & 4.4 & 5.4 \\
\hline active emergency response & 5.8 & 6.8 & 7.8 & 5.4 & 6.4 \\
\hline Emergency response speed & 4.8 & 6.8 & 6.8 & 5.2 & 7.2 \\
\hline system repair & 5.5 & 6.5 & 6.8 & 6.6 & 7.0 \\
\hline data backup repair & 7.6 & 5.6 & 6.2 & 4.8 & 4.6 \\
\hline security policy upgrade & 5.8 & 6.8 & 7.8 & 6.4 & 5.4 \\
\hline
\end{tabular}

From Table 4, we could get:

$$
\begin{aligned}
D^{(A)} & =\left(\begin{array}{lllll}
4.3 & 5.8 & 5.5 & 6.8 & 7.8 \\
8.2 & 7.8 & 8.3 & 7.5 & 8.5 \\
8.1 & 8.5 & 8.8 & 7.6 & 8.6 \\
3.5 & 5.2 & 4.3 & 3.0 & 6.0 \\
4.2 & 3.8 & 3.6 & 4.5 & 6.5 \\
3.8 & 4.3 & 4.8 & 3.2 & 5.2 \\
4.5 & 5.6 & 4.8 & 6.0 & 8.1 \\
4.0 & 3.2 & 4.1 & 3.9 & 5.9
\end{array}\right), D^{(B)}=\left(\begin{array}{llllll}
5.1 & 6.2 & 6.8 & 4.2 & 6.2 \\
6.2 & 5.4 & 4.2 & 4.8 & 6.8 \\
4.3 & 4.8 & 3.8 & 4.2 & 6.2 \\
5.2 & 5.5 & 4.8 & 3.8 & 5.8
\end{array}\right), \\
D^{(C)} & =\left(\begin{array}{lllll}
6.6 & 5.6 & 5.2 & 4.4 & 5.4 \\
5.8 & 6.8 & 7.8 & 5.4 & 6.4 \\
4.8 & 6.8 & 6.8 & 5.2 & 7.2
\end{array}\right), D^{(D)}=\left(\begin{array}{llllll}
5.5 & 6.5 & 6.8 & 6.6 & 7.0 \\
7.6 & 5.6 & 6.2 & 4.8 & 4.6 \\
5.8 & 6.8 & 7.8 & 6.4 & 5.4
\end{array}\right) .
\end{aligned}
$$

Calculate the 4 grey clustering coefficients of the first second-level factor of the main factor $A$ of computer network information security, namely:

$$
\tilde{\Theta}_{111}=\sum_{l=1}^{5} f_{1}\left(d_{1 l}\right)=f_{1}(4.3)+f_{1}(5.8)+f_{1}(5.5)+f_{1}(6.8)+f_{1}(7.8)=3.8 ;
$$




$$
\begin{aligned}
& \tilde{\Theta}_{211}=\sum_{l=1}^{5} f_{2}\left(d_{1 l}\right)=f_{2}(4.3)+f_{2}(5.8)+f_{2}(5.5)+f_{2}(6.8)+f_{2}(7.8)=3.8 ; \\
& \tilde{\Theta}_{311}=\sum_{l=1}^{5} f_{3}\left(d_{1 l}\right)=f_{3}(4.3)+f_{3}(5.8)+f_{3}(5.5)+f_{3}(6.8)+f_{3}(7.8)=4.2 ; \\
& \tilde{\Theta}_{411}=\sum_{l=1}^{5} f_{4}\left(d_{1 l}\right)=f_{4}(4.3)+f_{4}(5.8)+f_{4}(5.5)+f_{4}(6.8)+f_{4}(7.8)=2.5 .
\end{aligned}
$$

In the same way, we could get the 4 grey clustering coefficients of the second and third second-level factor of the main factor $A$ as follows:

$$
\begin{aligned}
& \tilde{\otimes}_{112}=5.0, \quad \tilde{\otimes}_{212}=4.9, \quad \tilde{\otimes}_{312}=3.3, \quad \tilde{\otimes}_{412}=0.1 ; \\
& \tilde{\otimes}_{113}=5.0, \quad \tilde{\otimes}_{213}=4.7, \quad \tilde{\otimes}_{313}=3.1, \quad \tilde{\otimes}_{413}=1.1 \text {; } \\
& \tilde{\otimes}_{114}=2.8, \quad \tilde{\otimes}_{214}=2.8, \quad \tilde{\otimes}_{314}=3.7, \quad \tilde{\otimes}_{414}=4.1 \text {; } \\
& \tilde{\otimes}_{115}=2.8, \quad \tilde{\otimes}_{215}=2.8, \quad \tilde{\otimes}_{315}=3.6, \quad \tilde{\otimes}_{415}=4.2 \text {; } \\
& \tilde{\otimes}_{116}=2.7, \quad \tilde{\otimes}_{216}=2.7, \quad \tilde{\otimes}_{316}=3.6, \quad \tilde{\otimes}_{416}=4.4 \text {; } \\
& \tilde{\otimes}_{117}=3.6, \quad \tilde{\otimes}_{217}=3.6, \quad \tilde{\otimes}_{317}=4.1, \quad \tilde{\otimes}_{417}=2.8 \text {; } \\
& \tilde{\otimes}_{118}=2.6, \quad \tilde{\otimes}_{218}=2.6, \quad \tilde{\otimes}_{318}=3.5, \quad \tilde{\otimes}_{418}=4.5 \text {. }
\end{aligned}
$$

Therefore, the grey coefficient matrix $\tilde{\otimes} R$ of the main factor $A$ could be obtained, namely:

$$
\tilde{\otimes} R_{A}=\left(\begin{array}{llll}
3.8 & 3.8 & 4.2 & 2.5 \\
5.0 & 4.9 & 3.3 & 0.1 \\
5.0 & 4.7 & 3.1 & 1.1 \\
2.8 & 2.8 & 3.7 & 4.1 \\
2.8 & 2.8 & 3.6 & 4.2 \\
2.7 & 2.7 & 3.6 & 4.4 \\
3.6 & 3.6 & 4.1 & 2.8 \\
2.6 & 2.6 & 3.5 & 4.5
\end{array}\right) .
$$

Using the bigger the optimal principle, the optimal solution of main factor $A$ could be determined as follows:

$$
\tilde{\otimes} R_{0}^{(A)}=\left[\begin{array}{cc} 
& M_{0} \\
c_{1} & 4.2 \\
c_{2} & 5.0 \\
c_{3} & 5.0 \\
c_{4} & 4.1 \\
c_{5} & 4.2 \\
c_{6} & 4.4 \\
c_{7} & 4.1 \\
c_{8} & 4.5
\end{array}\right] .
$$

Using the bigger the optimal criterion to carry on the standardized processing to $\tilde{\otimes} R_{A}$, the correlation grey matter element of the main factor $A$ could be obtained as follows: 


$$
\tilde{\otimes} R_{\xi}^{(A)}=\left(\begin{array}{cccc}
0.33 & 0.33 & 1 & 0.11 \\
1 & 0.96 & 0.59 & 0.33 \\
1 & 0.87 & 0.51 & 0.33 \\
0.33 & 0.33 & 0.62 & 1 \\
0.33 & 0.33 & 0.54 & 1 \\
0.33 & 0.33 & 0.52 & 1 \\
0.33 & 0.33 & 1 & 0.16 \\
0.33 & 0.33 & 0.49 & 1
\end{array}\right) .
$$

According to the formula (6), we could calculate:

$$
\tilde{\otimes} A=(0.1996,0.1123,0.0956,0.1178,0.0862,0.1530,0.1103,0.1252)\left(\begin{array}{cccc}
0.33 & 0.33 & 1 & 0.11 \\
1 & 0.96 & 0.59 & 0.33 \\
1 & 0.87 & 0.51 & 0.33 \\
0.33 & 0.33 & 0.62 & 1 \\
0.33 & 0.33 & 0.54 & 1 \\
0.33 & 0.33 & 0.52 & 1 \\
0.33 & 0.33 & 1 & 0.16 \\
0.33 & 0.33 & 0.49 & 1
\end{array}\right)
$$

$=(0.4693,0.4524,0.6854,0.5904)$

In the same way, we could get:

$$
\begin{gathered}
\tilde{\otimes} B=(0.3997,0.3997,0.9240,0.5102) ; \tilde{\otimes} C=(0.6553,0.6553,1,0.3300) ; \\
\tilde{\otimes} D=(0.7576,0.7576,1,0.3300) .
\end{gathered}
$$

Finally, we could get the overall correlation coefficient of computer network information security of Weifang University of Science and Technology as follows:

$$
\tilde{\otimes} P=(0.5653,0.5588,0.8677,0.4590),
$$

According to the maximum membership degree principle, the grey clustering level of computer network information security of Weifang University of Science and Technology could be judged as general risk.

\section{Conclusion}

In recent years, with the development of computer network and the progress of science and technology, the problems of network information security become a focus of our society. The evaluation system of network security is very complicated, which needs to use multi-level fuzzy indexes. Therefore, most people use the fuzzy comprehensive evaluation model. In this paper, the grey matter-element method is used to study computer network information security, which provides a more reasonable and scientific method for evaluating network information security. 


\section{References}

[1] R. Amadio and D. Lugiez, "On the reachability problem in cryptographic protocols", in: International

[2] V. Atlur and W. K. Huang, "An extended petrinet model for supporting workflows in a multilevel secure environment [J]", Proceedings of the 10th IFIP WG 11.3 Working Conference on Database Security, (1996), pp. 199-216.

[3] Y.-c. zhang, "Chinese geological hazard risk analysis and hazard regionalization", Marine geology and quaternary geology, vol. 15, no. 3, (1995), pp. 55-67.

[4] F. Hongqi and Y. Minzhong, "Principle of urban engineering geological environmental analysis", Beijing, China building industry press, (1999).

[5] C. H. Bin, whereas haidong539 and J.-z. Wang, "Analytic hierarchy process (ahp) application of geologic hazard risk division in taihang mountain", Chinese journal of geological hazards and prevention, vol. 14, no. 3 .

[6] HongJiang and Z.-g. Liu, "Fuzzy mathematics comprehensive evaluation method in the application of the regional geological environmental quality evaluation", Engineering geological, hydrogeological, (1996).6, pp. 44-55.

[7] M. Tongxia, S. Hongren and Z. Lijun, "Quantitative evaluation and prediction of regional geological environment", Geological front, vol. 3, no. 1-2, (1996).

[8] F. YuMing, "GIS and its application in geological hazard research", Dr. Huang, the first three national youth engineering geological symposium corpus, chengdu university of science and technology press, (1992), pp. 510-519.

[9] Z. Jun and D. Dong, "chrysanthemum, such as regional geological hazard environment system and the basic idea of comprehensive evaluation model", Chinese journal of geological hazards and prevention, (1994), vol. 5, no. 4, pp. 26-32.

[10] J. lyang, "Geological hazard risk evaluation theory and method", Geology and mineral resources of China economy, no. 4, (1996), pp. 40-45.

[11] L.-k. Jiang, "The application of the fuzzy consistent matrix in the analytic hierarchy process (ahp)", Journal of Shanghai maritime university, vol. 12, no. 2, (1998), pp. 55-60.

[12] J.-j. Zhang, "Fuzzy analytic hierarchy process (quantificating), Fuzzy sets and systems, vol. 14, no. 2, (2000), pp. 80-88.

[13] Y.-j. lv, "Sort of fuzzy analytic hierarchy process (ahp) based on fuzzy consistent matrix", Fuzzy sets and systems, no. 2, (2002), pp. 79-85.

[14] L. Tao, "The Application of Fuzzy Mathematics in Satisfaction Degree of Customers in Supermarket[J]", Journal of Capital Normal University, no. 3, (2015), pp. 15-18.

[15] L. Tao, "The environment impact evaluation based on urban land planning project[J]", International Journal of Earth Sciences and Engineering, 2015(2).

[16] H. Zhonggeng, "Mathematical Modeling and Its Application [M]", Beijing: Higher Education Press, (2005).

[17] B. Huabai and B. Shizhen, "Two-Layer Fuzzy Comprehensive RSA-ANP-DSS Evaluation Model of Emergency Management Capacity about Enterprise Value Network[J]”, Systems Engineering Procedia, vol. 5, (2012), pp. 93-98.

[18] S. Jingwei and W. Xinyi, "Application of fuzzy mathematics in comprehensive evaluation of the quality of the physical and chemical laboratories [J]", Shanghai Journal of Preventive Medicine, vol. 14, (2002) June, pp. 265-266. 